\title{
The volatile anesthetic sevoflurane attenuates ventilator-induced lung injury through inhibition of ERK1/2 and Akt signal transduction
}

\author{
Sang-Hun $\mathrm{Kim}^{1}$, Mei $\mathrm{Li}^{3}$, Tae-Hee Pyeon ${ }^{2}$, Keum-Young So ${ }^{1}$, and \\ Sang-Hyun Kwak ${ }^{2}$ \\ Department of Anesthesiology and Pain Meidicne, ${ }^{1}$ Chosun University Medical School, ${ }^{2}$ Chonnam National \\ University Medical School, Gwangju, Korea, ${ }^{3}$ Department of Anesthesiology, Zhejiang University School of \\ Medicine, Hangzhou, China
}

\begin{abstract}
Background: Ventilator-induced lung injury (VILI) sustained during mechanical ventilator support is still a cause of a high rate of morbidity and mortality in intensive care units and in operating rooms. VILI is characterized by pulmonary inflammation that appears to be mediated by proinflammatory cytokines. This study investigates whether the volatile anesthetic sevoflurane has an anti-inflammatory effect that attenuates VILI.

Methods: Twenty one male rabbits were anesthetized and were mechanically ventilated with $50 \%$ oxygen at a peak inspiratory pressure (PIP) of $10 \mathrm{cmH}_{2} \mathrm{O}$, I : E ratio of $1: 4$, and positive end expiratory pressure of $5 \mathrm{cmH}_{2} \mathrm{O}$. All animals were randomly assigned to one of three groups that were ventilated for $5 \mathrm{~h}$ with $10 \mathrm{cmH}_{2} \mathrm{O}$ of PIP (Sham group, $\mathrm{n}=7$ ); $30 \mathrm{cmH}_{2} \mathrm{O}$ of PIP (Control group, $\mathrm{n}=7$ ); or $30 \mathrm{cmH}_{2} \mathrm{O}$ of PIP and $0.8 \mathrm{vol} \%$ sevoflurane (Sevoflurane group, $\mathrm{n}=7$ ). The wet/dry weight (W/D) ratio and histopathology of the lung; concentration of interleukin-8 (IL-8) in the bronchoalveolar lavage fluid; and activation of extracellular signal-regulated kinases (ERK) 1/2, p38 mitogen-activated protein kinase, and Akt were measured in the lung tissue after completing the protocol.

Results: Histopathology indicated that the sevoflurane group showed fewer inflammatory cells and architectural changes than the control group did. The W/D ratio [(5.36 \pm 0.13$)$ versus $(6.61 \pm 0.20)]$, expression of IL-8 [(144.08 \pm 14.61$)$ versus $(228.56 \pm 15.13) \mathrm{pg} / \mathrm{ml}]$ and phosphorylation of ERK1/2 and Akt decreased significantly in the sevoflurane group relative to the control group.

Conclusions: Sevoflurane attenuates VILI in rabbits mainly by inhibiting expression of IL-8, and Sevoflurane-induced inhibition of phosphorylated ERK1/2 and Akt might be a possible pathway for protection. (Korean J Anesthesiol 2015; 68: 62-69)
\end{abstract}

Key Words: Akt, ERK1/2, Sevoflurane, Ventilator-induced lung injury.

Corresponding author: Sang-Hyun Kwak, M.D., Ph.D.

Department of Anesthesiology and Pain Medicine, Chonnam

National University Medical School, 42, Jebong-ro, Dong-gu,

Gwangju 501-757, Korea

Tel: 82-62-220-6895, Fax: 82-62-232-6294

E-mail: shkwak@jnu.ac.kr

Received: February 27, 2014.

Revised: 1st, July 2, 2014; 2nd, July 29, 2014.

Accepted: August 26, 2014.

Korean J Anesthesiol 2015 February 68(1): 62-69

http://dx.doi.org/10.4097/kjae.2015.68.1.62

\section{Introduction}

Mechanical ventilation (MV), a life-saving intervention for critically ill patients with respiratory failure caused by acute lung injury (ALI), can cause an inflammatory response in both diseased and normal lungs. MV itself can also cause ventilator-induced lung injury (VILI), a form of ALI [1]. VILI results not only from barotraumas caused by alveolar disruption, capillary leakage, or lung edema, but also from biotraumas caused by the secretion of pro-inflammatory cytokines and mediators in pulmonary cells

(c) This is an open-access article distributed under the terms of the Creative Commons Attribution Non-Commercial License (http://creativecommons.org/ licenses/by-nc/3.0/), which permits unrestricted non-commercial use, distribution, and reproduction in any medium, provided the original work is properly cited. 
$[1,2]$. In particular, a complex pro- and anti-inflammatory immune reaction occurs when mechanical ventilation with high tidal volume and high inspiratory pressure is conducted on patients that require high ventilation pressure to maintain appropriate oxygenation and to remove $\mathrm{CO}_{2}$, and an imbalance eventually occurs as the inflammatory reactions progress, leading to the deterioration of ALI [3,4].

Many studies have reported that volatile anesthetics can play an important role in the protection of major organs, such as the heart and lung, through their preconditioning and postconditioning effects $[5,6]$. Although the mechanism through which volatile anesthetics provide organ protection is not clear, recent studies have reported that isoflurane and halothane had antiinflammatory effects and reduced lung injury caused by lipopolysaccharide (LPS) and also reduced the pro-inflammatory cytokines secreted after MV stimulation [7,8]. Sevoflurane was also reported to have inhibited the inflammatory response after pretreatment with sevoflurane in endotoxin-induced shock and ischemia-reperfusion models $[9,10]$. The present study was conducted to determine whether or not sevoflurane, a commonly used volatile anesthetic, attenuates ventilator-induced lung injury in a rabbit model and also to clarify the effect sevoflurane has on the production of pro-inflammatory cytokines, such as interleukin-8 (IL-8), and the activation of intracellular signaling pathways, such as extracellular signal-regulated kinase (ERK) 1/2, p38 mitogen-activated protein kinase (MAPK), and Akt.

\section{Materials and Methods}

\section{Animal preparation}

Male New Zealand white rabbits, $1.8-2.2 \mathrm{~kg}$ of weight, were purchased from Samtako Science (O-San, Korea). The rabbits were kept on a $12 \mathrm{~h}$ light/dark cycle with access to food and water ad libitum. All experiments were conducted in accordance with institutional review board-approved protocols. The rabbits were initially anesthetized with ketamine hydrochloride $(30 \mathrm{mg} /$ $\mathrm{kg}$, i.m.) and xylazine hydrochloride $(0.2 \mathrm{mg} / \mathrm{kg}$, i.m.). An intravenous $24 \mathrm{G}$ medicut was inserted into an auricular vein to provide a route for administration of the fluid and the drugs. Normal saline was infused at a rate of $15 \mathrm{ml} / \mathrm{kg} / \mathrm{hr}$ until the end of the study. A tracheostomy was performed aseptically, and a 3.5 $\mathrm{mm}$ uncuffed endotracheal tube was inserted into the trachea with spontaneous ventilation. After the start of a continuous infusion of ketamine $(3 \mathrm{mg} / \mathrm{kg} / \mathrm{hr})$ and vecuronium bromide $(0.05 \mathrm{mg} / \mathrm{kg} / \mathrm{hr})$ to maintain anesthesia and muscle paralysis, the lungs of the rabbit were mechanically ventilated with $50 \%$ oxygen using a pressure-controlled ventilator (PB 840, SiemenElema, Solna, Sweden). MV were initially set to $10 \mathrm{cmH}_{2} \mathrm{O}$ of peak inspiratory pressure (PIP), I : E ratio of $1: 4$, and $5 \mathrm{cmH}_{2} \mathrm{O}$ of positive end expiratory pressure (PEEP). The respiratory rate was controlled to produce an initial arterial carbon dioxide tension $\left(\mathrm{PaCO}_{2}\right)$ of $35-45 \mathrm{mmH}_{2} \mathrm{O}$, and the rabbits were placed on a heating pad under a radiant heating lamp to keep their body temperature between 36.5 and $37.5^{\circ} \mathrm{C}$ at the esophagus. The arterial catheter was placed in the aorta through the right common carotid artery cut-down to monitor arterial pressure and to harvest blood samples for blood gas analysis and assay. Then, we measure the baseline values of the mean blood pressure and arterial blood gas at $0.5 \mathrm{~h}$ after the start of the initial MV.

\section{Experimental protocols}

All animals were randomly assigned to one of three groups ventilated with $10 \mathrm{cmH}_{2} \mathrm{O}$ of PIP (Sham group, $\mathrm{n}=7$ ); $30 \mathrm{~cm}$ $\mathrm{H}_{2} \mathrm{O}$ of PIP (Control group, $\mathrm{n}=7$ ); or $30 \mathrm{cmH}_{2} \mathrm{O}$ of PIP and 0.8 vol\% sevoflurane (Sevorane ${ }^{\circledR}$, Abbott, Barr, Switzerland) (Sevoflurane group, $\mathrm{n}=7$ ). The respiratory rate was set to maintain a normal $\mathrm{PaCO}_{2}$, respectively. These settings were maintained constant during the $5 \mathrm{~h}$ of MV with 0.5 fraction of inspired oxygen $\left(\mathrm{FIO}_{2}\right)$. The arterial blood samples for the blood gas analysis were obtained at 0.5 and $5 \mathrm{~h}$ after the start of the experiment, and then all rabbits were killed at $5 \mathrm{~h}$ after the start of experiment by injection of an overdose of thiopental sodium. Immediately after the rabbits were killed, the thorax was opened, and the lungs were removed en bloc by observers unaware of the nature of the experiment.

\section{Arterial blood gas analysis}

Arterial blood specimens were analyzed for $\mathrm{PaO}_{2}, \mathrm{PaCO}_{2}$, and $\mathrm{pH}$ using a blood gas analyzer (GEM Premier Plus, Instrumentation Laboratory, Lexington, MA, USA).

\section{Wet to dry weight (W/D) ratio of the lungs}

The left upper lobe of the lung was weighed and then dried to a constant weight at $60^{\circ} \mathrm{C}$ for over $48 \mathrm{~h}$ in an oven. The W/D ratio was calculated to assess tissue edema [11].

\section{Histopathological examination}

The left lower lobe was fixed by instillation of a $10 \%$ formaldehyde solution through the left lower bronchus at $20 \mathrm{cmH}_{2} \mathrm{O}$. The lungs were then embedded in paraffin, and the sections were stained with hematoxylin and eosin. Two observers, unaware of the nature of the experiment, scored the lung injuries under light microscopy from 0 (no damage) to 4+ (maximum damage) according to the combined assessment of alveolar congestion, hemorrhage, edema, infiltration/aggregation of neutro- 
phils in the airspace or vessel wall, thickness of the alveolar wall, and hyaline membrane formation [11].

\section{Preparation of bronchoalveolar lavage fluid (BALF)}

BALF was harvested from the right-middle and -lower lobes. The right mainstem bronchus was the site for slow infusion and extraction of $35 \mathrm{ml}$ of saline, three times. The saline contained ethylendiamine-tetraacetic acid-2 $\mathrm{Na}$ and was cooled to $4^{\circ} \mathrm{C}$ to prevent the metabolism of leukocytes. Indomethacin $(5 \mu \mathrm{mol})$ was added to the BALF to inhibit further metabolism of arachidonic acid to prostaglandins during analysis. The BALF was centrifuged at $250 \mathrm{~g}$ at $4^{\circ} \mathrm{C}$ for $20 \mathrm{~min}$ to remove the cells. The cell-free supernatant was then divided into several aliquots and was stored at $-80^{\circ} \mathrm{C}$ to measure the various mediators.

\section{Measurement of IL-8}

The concentration of IL- 8 in BALF was quantified by using an ELISA kit obtained from R\&D Systems (Minneapolis, MN, USA) according to the manufacturer's instructions.

\section{Western blot analysis}

The upper lobe of the right lung was removed from the rabbit, and whole cell extracts were prepared from lung tissue by homogenization in a protein extraction solution (PRO-PREPTM, Intron biotechnology, Seoul, Korea). Then the cell extracts were re-suspended in ice for $20 \mathrm{~min}$, and debris from the lysed cells was pelleted by centrifugation at 13,000 rpm for $10 \mathrm{~min}$. The protein concentration of each sample was assayed using the bicinchoninic acid (BCA) protein assay kit (Pierce, WI, USA), standardized to BSA according to the manufacturer's protocol. For Western blot analysis, $30 \mu \mathrm{g}$ of protein were loaded and run on a $10 \%$ Tris- $\mathrm{HCl}$ SDS polyacrylamide gel. The protein was electrotransferred to a polyvinylidene difluoride membrane and was then blocked with $5 \%$ nonfat dry milk in $20 \mathrm{mM}$ of tris buffer saline (TBS) with $0.1 \%$ Tween. After blocking, the membrane was incubated overnight at $4^{\circ} \mathrm{C}$ with rabbit polyclonal specific primary $\mathrm{Ab}$ to $\mathrm{p}$-ERK or p-p38 using a dilution of $1 / 1,000$ in $1 \%$ BSA, followed by anti-rabbit or anti-rat IgG, Horse Radish Peroxidase (HRP)-coupled secondary antibody at a dilution of $1 / 2000$ in $5 \%$ nonfat dry milk. After washing three times, the bands were detected using ECL Western blotting detection reagents (Santa Cruz Biotechnology, Santa Cruz, CA, USA) and were then imaged with LAS-3000 (Life-science, Fujifilm Global, Tokyo, Japan). The membranes were then stripped using a stripping buffer (Pierce, Wisconsin, USA), and were reprobed with antibodies specific for total ERK or p38. Densitometry was performed using the Multi gauge V3.0 chemiluminescence system and analysis software (Life-science, Fujifilm Global, Tokyo, Japan) to determine the ratio between the phosphorylated and the total kinases.

\section{Statistical analysis}

The SPSS 12.0 for Windows software (SPSS Inc., Chicargo, IL, USA) was used to conduct the statistical analyses. Data from experiments are expressed as mean \pm SEM. First, the importance of the significance between groups was assessed using a Kruskal-Wallis test followed by a multi comparison with Dunnett's method. A value of $\mathrm{P}<0.05$ was considered to be statistically significant.

\section{Results}

\section{Arterial blood gas analysis}

MV with high inspiratory pressure resulted in a significant decrease of $\mathrm{PaO}_{2} / \mathrm{FIO}_{2}$ in the control and sevoflurane groups relative to the sham group. Also, the sevoflurane group had a

Table 1. The Arterial Blood Gas Analysis and Hemodynamic Responses Throughout the Experimental Protocol in Each Group

\begin{tabular}{|c|c|c|}
\hline \multicolumn{3}{|c|}{ Time after the start of the initial mechanical ventilation (MV) } \\
\hline Group & $0.5 \mathrm{~h}$ & $5.5 \mathrm{~h}$ \\
\hline \multicolumn{3}{|l|}{$\mathrm{pH}$} \\
\hline Sham & $7.47 \pm 0.04$ & $7.27 \pm 0.03$ \\
\hline Control & $7.43 \pm 0.06$ & $7.42 \pm 0.09$ \\
\hline Sevoflurane & $7.44 \pm 0.04$ & $7.41 \pm 0.08$ \\
\hline \multicolumn{3}{|l|}{$\mathrm{PaO}_{2}(\mathrm{mmHg})$} \\
\hline Sham & $248.50 \pm 7.05$ & $231.75 \pm 11.21$ \\
\hline Control & $240.00 \pm 4.08$ & $175.00 \pm 9.97^{*}$ \\
\hline Sevoflurane & $252.50 \pm 6.61$ & $207.50 \pm 1.91^{*, \dagger}$ \\
\hline \multicolumn{3}{|l|}{$\mathrm{PaCO}_{2},(\mathrm{mmHg})$} \\
\hline Sham & $42.25 \pm 2.22$ & $45.50 \pm 1.29$ \\
\hline Control & $42.00 \pm 2.45$ & $37.75 \pm 1.71 *$ \\
\hline Sevoflurane & $42.25 \pm 1.71$ & $39.25 \pm 0.96^{*}$ \\
\hline \multicolumn{3}{|l|}{$\mathrm{PaO}_{2} / \mathrm{FIO}_{2}$ ratio } \\
\hline Sham & $497.00 \pm 14.09$ & $463.50 \pm 22.41$ \\
\hline Control & $480.00 \pm 8.16$ & $350.00 \pm 19.93 *$ \\
\hline Sevoflurane & $505.00 \pm 13.22$ & $415.00 \pm 3.83^{*, \dagger}$ \\
\hline \multicolumn{3}{|c|}{ Heart rate $(/ \mathrm{min})$} \\
\hline Sham & $205.25 \pm 17.04$ & $237.75 \pm 24.50$ \\
\hline Control & $205.00 \pm 12.36$ & $234.75 \pm 18.17$ \\
\hline Sevoflurane & $210.75 \pm 12.42$ & $238.50 \pm 17.00$ \\
\hline \multicolumn{3}{|c|}{$\begin{array}{l}\text { Mean arterial pressure } \\
(\mathrm{mmHg})\end{array}$} \\
\hline Sham & $58.25 \pm 7.59$ & $104.25 \pm 11.95$ \\
\hline Control & $55.50 \pm 10.28$ & $82.00 \pm 16.79$ \\
\hline Sevoflurane & $44.00 \pm 6.68$ & $86.25 \pm 6.55$ \\
\hline
\end{tabular}

Data are shown as mean \pm SEM. Sham group $(\mathrm{N}=7)$, control group $(\mathrm{N}$ $=7$ ) and sevoflurane group $(\mathrm{N}=7) . \mathrm{N}$ indicates the number of rabbits. ${ }^{*} \mathrm{P}<0.05$ compared with sham group. ${ }^{\dagger} \mathrm{P}<0.05$ compared with control group. 


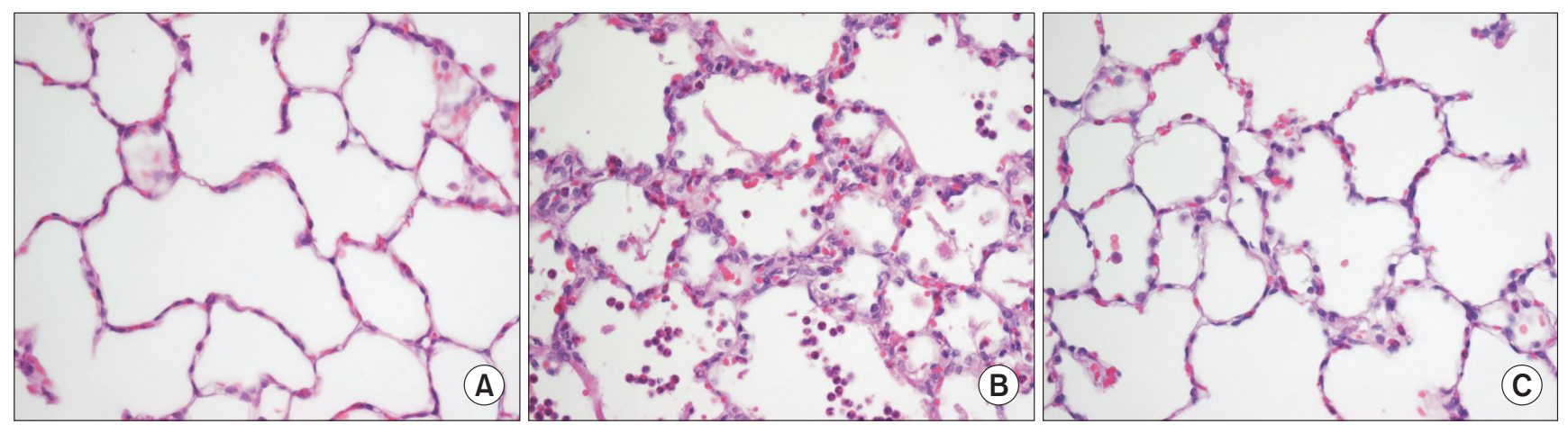

Fig. 1. Representative histological lung tissue sections (magnification $400 \times$, hematoxylin and eosin-stained). (A) The samples in the sham group (N = 7) was free of edema and cellular infiltrate. (B) Control group $(\mathrm{N}=7)$. Interstitial edema, type II pneumocyte proliferation and inflammatory cell infiltration in the alveoli and interstitium was detected. (C) Sevoflurane group $(\mathrm{N}=7)$. The lungs of the sevoflurane-treated animals showed almost normal lung architecture and only minor signs of cell influx.

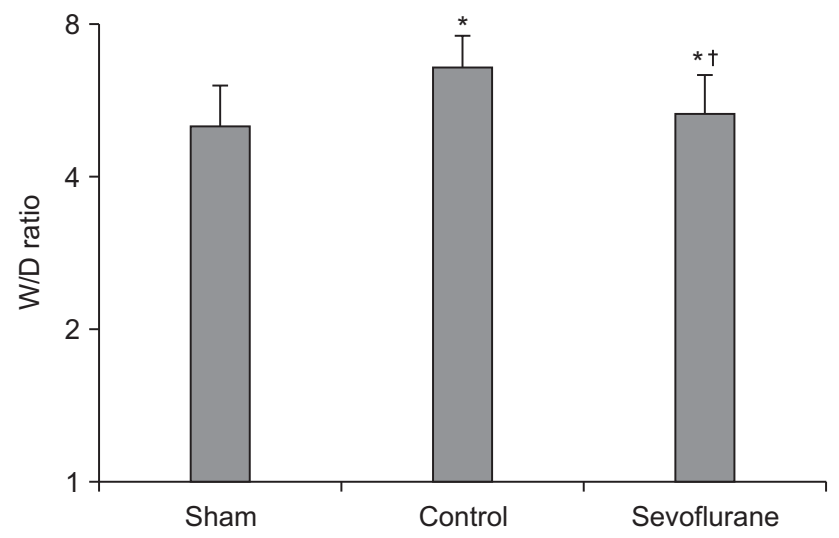

Fig. 2. Wet to dry weight (W/D) ratio of the lungs. Shame group $(\mathrm{N}$ $=7)$, control group $(\mathrm{N}=7)$ and servoflurane group $(\mathrm{N}=7) . * \mathrm{P}<0.05$ compared to the sham group $(\mathrm{N}=7) .{ }^{\dagger} \mathrm{P}<0.05$ compared to the control group. Data are shown as mean \pm SEM. $\mathrm{N}$ indicates the number of rabbits.

Table 2. Lung Injury Score of Each Group at the End of the Experiment

\begin{tabular}{cccc}
\hline Group & $\begin{array}{c}\text { Sham } \\
(\mathrm{N}=7)\end{array}$ & $\begin{array}{c}\text { Control } \\
(\mathrm{N}=7)\end{array}$ & $\begin{array}{c}\text { Sevoflurane } \\
(\mathrm{N}=7)\end{array}$ \\
\hline Lung injury score $(0-4)$ & 0 & $2.25 \pm 0.96 *$ & $0.75 \pm 0.50^{\dagger}$ \\
\hline
\end{tabular}

Data are shown as mean \pm SEM. $\mathrm{N}$ indicates the number of rabbits. $* \mathrm{P}$ $<0.05$ compared with sham group. ${ }^{\dagger} \mathrm{P}<0.05$ compared with the control group.

significantly higher $\mathrm{PaO}_{2} / \mathrm{FIO}_{2}$ ratio compared to that of the control group $5 \mathrm{~h}$ after the start of the experiment $(\mathrm{P}<0.05$, Table 1). Arterial carbon dioxide tension levels were similar in the sevoflurane and in the control group, with no significant differences (Table 1).

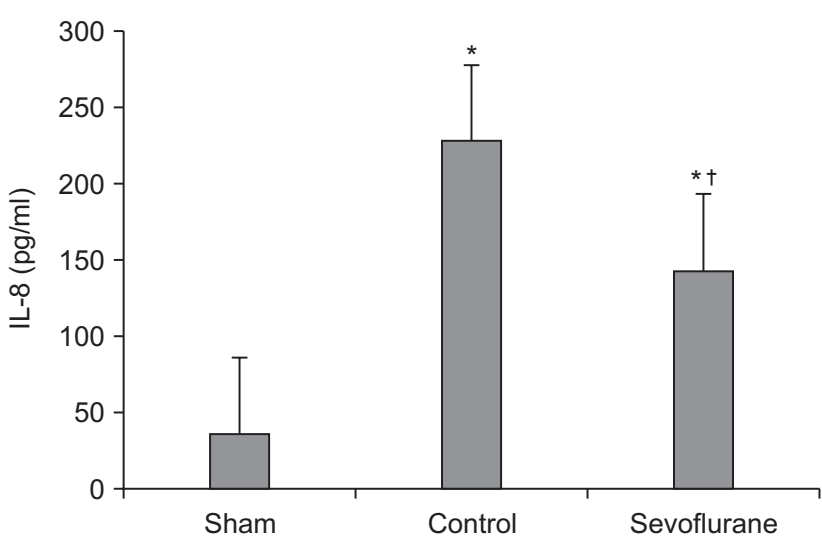

Fig. 3. IL-8 in bronchoalveolar lavage fluid. Shame group $(\mathrm{N}=7)$, control group $(\mathrm{N}=7)$ and servoflurane group $(\mathrm{N}=7)$. $* \mathrm{P}<0.05$ compared to the sham group $(\mathrm{N}=7) .{ }^{\dagger} \mathrm{P}<0.05$ compared to the control group. Data are shown as mean \pm SEM. $\mathrm{N}$ indicates the number of rabbits.

\section{Circulatory variables}

The heart rates and mean arterial pressure were similar between the control and the sevoflurane groups, showing no significant differences in the heart rates and in the mean arterial pressure between the study groups at any time (Table 1).

\section{Histopathological analysis}

As expected, mechanical ventilation with a high inspiratory pressure resulted in an interstitial edema with inflammatory cell recruitment (Fig. 1). The lung injury score of the sevoflurane group was significantly lower than in the control group $(\mathrm{P}<0.05$, Table 2). 


\section{Lung wet weight to dry weight (W/D) ratio}

The W/D ratio was significantly lower in the sevoflurane group than in the control group, indicating a lower lung water content $[(5.36 \pm 0.13)$ versus $(6.61 \pm 0.20)$, respectively] $(\mathrm{P}<0.05$, Fig. 2).

\section{IL-8 in bronchoalveolar lavage fluid}

Seventy five percent of the administered BALF was retrieved. The IL-8 levels were significantly lower in the sevoflurane group

A
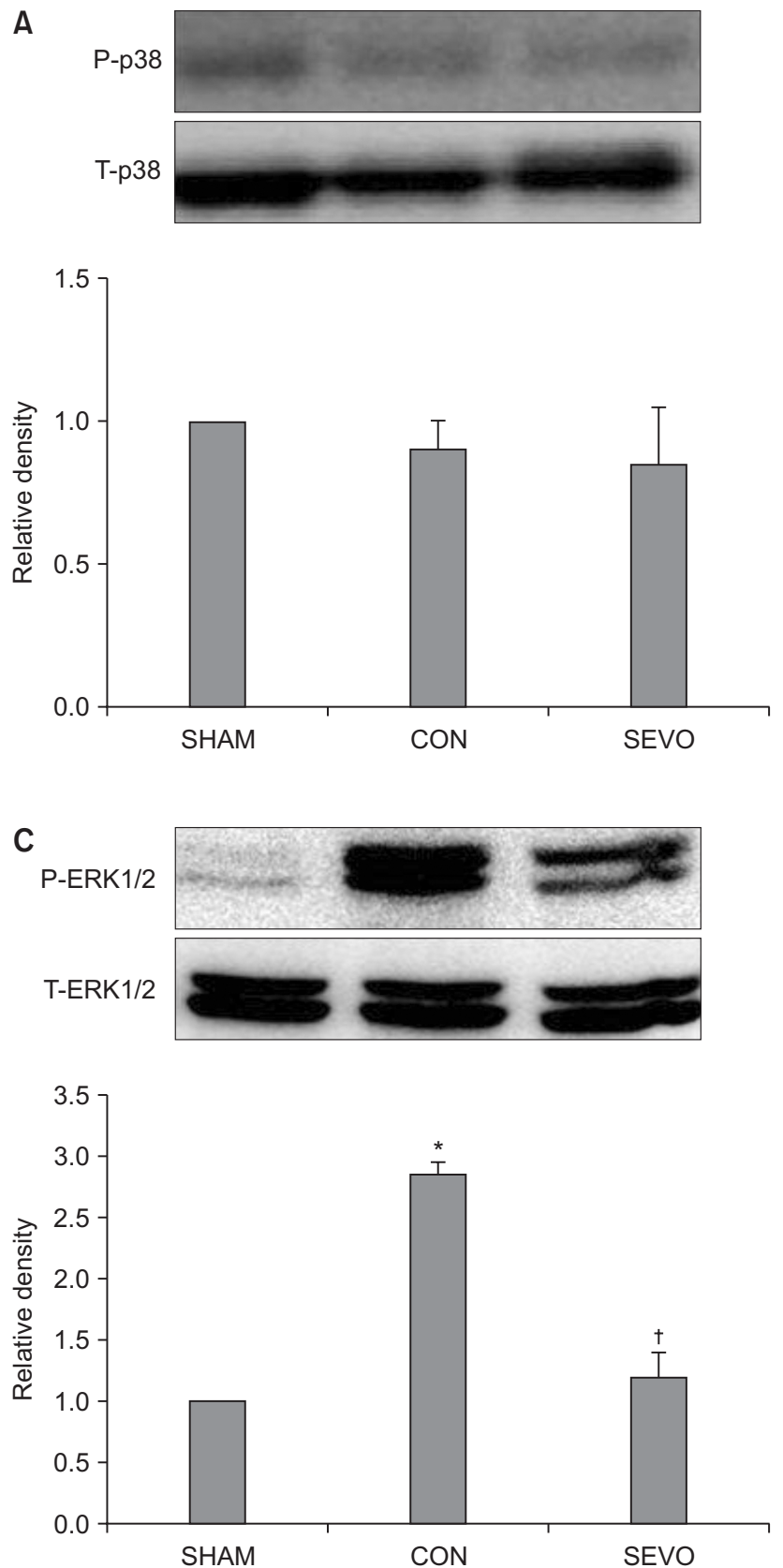

than in the control group after $5 \mathrm{~h}$ of MV with high inspiratory pressure $[(144.08 \pm 14.61)$ versus $(228.56 \pm 15.13) \mathrm{pg} / \mathrm{ml}$, respectively] ( $\mathrm{P}<0.05$, Fig. 3).

\section{Western blot analysis}

We performed Western blot analysis of the lung homogenates to determine the expression levels of several anti-apoptotic or survival protein kianses (Akt, p-Akt, p38, p-p38, ERK1/2, pERK1/2) in order to elucidate the molecular mechanism through which sevoflurane becomes involved in the signal transduction

B
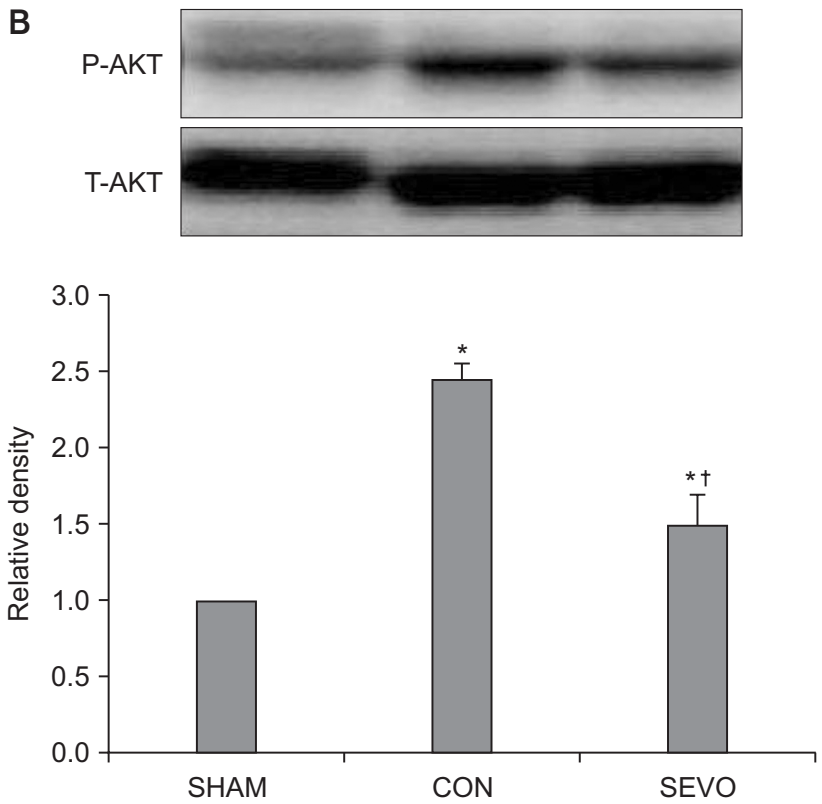

Fig. 4. p38 Mitogen-activated protein kinase, extracellular signal regulated kinase (ERK) and Akt phosphorylation in the lung of sham (SHAM, $\mathrm{N}=7$ ), control (CON, $\mathrm{N}=7$ ) and sevoflurane (SEV, $\mathrm{N}=7$ ) group. The sevoflurane group significantly attenuated the expression of $\mathrm{p}$-Akt and p-ERK1/2 $(B, C)(P<0.05)$. Data are represented as mean \pm SEM. $N$ indicates the number of independent experiments. ${ }^{*} \mathrm{P}<0.05$ compared to the Sham group. ${ }^{\dagger} \mathrm{P}<0.05$ compared to the control group. 
responsible for pulmonary protection during MV with a high inspiratory pressure. Sevoflurane significantly attenuated the expression of p-Akt and p-ERK1/2 (P < 0.05, Fig. 4). There were no significant differences in the levels of $\mathrm{p}-\mathrm{p} 38$ between the control and sevoflurane groups. Western blot analyses indicated that sevoflurane-treated lungs had a decreased activation of p-Akt and $\mathrm{p}$-ERK1/2, which may be associated with lung protection after MV with a high inspiratory pressure for $5 \mathrm{~h}$.

\section{Discussion}

In this study, sevoflurane was observed to attenuate lung injury by decreasing the expression of the pro-inflammatory mediator IL-8 and reducing the phosphorylation of ERK1/2 and Akt in an in vivo model of VILI. These findings appear to be related to the anti-inflammatory properties of sevoflurane, including the attenuation of cytokine IL- 8 production via inhibition of ERK1/2 and Akt phosphorylation in an in vivo VILI model.

Inflammatory cells and inflammatory mediators play important roles in the pathogenesis of VILI where MV with a large tidal volume or high inspiratory pressure was reported to have exhibited an inflammatory response indistinguishable from morphological and histological changes caused by the presence of bacterial lipopolysaccharides (LPS) [12]. Tsuno et al. [13] reported that lung injuries caused by over-inflation during MV resulted in alveolar hemorrhages, alveolar neutrophil infiltration, alveolar macrophage and type II pneumocyte proliferation, interstitial congestion and thickening, and interstitial lymphocyte infiltration and hyaline membrane. These findings were were similar to those in the early stage of ARDS. Inflammatory cytokines, such as tumor necrosis factor (TNF)- $\alpha$ and interleukin (IL)-8, also play an important role in VILI [14]. However, it is not yet clear if injurious ventilation itself induces cytokineinduced pulmonary inflammation in a situation in which there is no preceding injury [15]. Whether or not TNF- $\alpha$ is associated with VILI exclusively as a result of MV has not been clarified in many in vivo and in vitro studies $[2,9,16]$. On the other hand, more consistent conclusions with respect to IL- 8 have been made [16]. IL- 8 release was induced, whereas TNF- $\alpha$ release was not seen in ex vivo studies using isolated lung cells exposed to high tidal volumes and alveolar epithelial cells exposed to cyclic pressure-stretching strains, respectively $[17,18]$. In addition, TNF- $\alpha$ release was not observed whereas IL- 8 release was seen in the BALF of rats that underwent $M V$ in vivo [16]. In this study, IL-8 significantly increased in the rabbits that had no preceding lung injuries five hours after MV with high inspiratory pressure. IL- 8 increased in the group treated with sevoflurane as well, but the magnitude of the increase was less than that of the control group. Thus, IL-8 is likely to play an important role in VILI.
The cellular signaling of protein kinase B (Akt) and extracellular-signal-regulated kinases $1 / 2$ (ERK1/2), which were reported to be associated with lung injury, was a special area of interest in this study. Increased Akt activity has been known to be associated with lung injuries and neutrophil migration to the injured site. A study on lung injury due to hemorrhaging reported that the lung was protected by attenuating inflammatory responses as a result of the inhibition of ERK phosphorylation by administering an ERK inhibitor [19]. In this molecular pathway, the up-regulation of Akt and EKR1/2 were reported to play an important role in the induction of inflammation by the ventilator and to provide the underlying mechanism for VILI $[20,21]$. In this in vivo study on rabbits, the phosphorylation of ERK1/2 and Akt significantly increased when the ventilator caused a lung injury, unlike in the sham group. Likewise, the phosphorylation of ERK1/2 and Akt increased more in the sevoflurane group than in the sham group, but an attenuation of the phosphorylation of ERK and Akt was more significantly seen in the sevoflurane group than in the VILI group. Taken together, putative cellular signaling pathway associated with sevofluraneinduced production of VILI is as follows : the IL- 8 inhibition of sevoflurane probably occurs through pathways that converge on ERK1/2 or Akt because these kinases regulate the production of IL-8 in the inflammatory response [12].

Volatile anesthetics have attracted attention as alternatives to conventional intravenous intensive care unit (ICU) sedation since the approval of the use of the Anesthetic Conserving Devices in Europe in 2005 [22]. Relative to intravenous sedatives, however, sevoflurane-inhaled sedation has been studied in relatively small populations of patients [22,23]. Studies on sevoflurane used for ICU sedation reported that shorter extubation and ventilator times were seen when end-tidal $0.5-1.0$ vol\% sevoflurane was used, and no negative effects on major organ functions, such as renal function, were observed [22,23]. For example, Cho et al. [24] reported that $1.5-2.5$ vol\% sevoflurane attenuates systemic and pulmonary inflammatory responses induced by a cardiopulmonary bypass. Furthermore, the ideal concentration of sevoflurane for pre- or post-conditional situations has not yet been established. Lee et al. [25] reported that volatile anesthetics had anti-inflammatory properties, and the maximal effect on sevoflurane ischemic protection was achieved with 1.1 vol\% in the kidney proximal tubule. A study on alveolar epithelial cells reported that a reduction of inflammatory mediators was achieved when the inflammatory mediators were stimulated by LPS for $2 \mathrm{~h}$, followed by exposure to a $2.2 \mathrm{vol} \%$ sevoflurane concentration for $4 \mathrm{~h}$ [26]. In a study on the postconditioning effects of various concentrations of volatile anesthetic sevoflurane used on inflammatory mediator expression via LPS stimulation in alveolar macrophages, inflammatory mediator expression was significantly reduced with a $3.3 \mathrm{vol} \%$ concentration of sevoflu- 
rane but increased with a 4.4 vol\% concentration of sevoflurane [6].

Several studies have contradicted this result by reporting that inflammatory mediator expression was stimulated by volatile anesthetics [27]. Kotani et al. [28] reported that the gene expression of pro-inflammatory cytokines increased and that inflammatory responses were induced within $2 \mathrm{~h}$ after sevoflurane inhalation during MV. Abou-Elenain [27] reported that more intrapulmonary pro-inflammatory responses were induced by sevoflurane during chest surgery. The aforementioned contradictory results are likely to have been due to the differences in each study's experimental setup, volatile anesthetics concentration, and time of exposure. In this animal study, 0.8 vol\% sevoflurane was used, which was less than 1 vol\%. Such a concentration is hemodynamically safe and can be clinically used for sedation.

This study had a few limitations. First, the sevoflurane concentration that would adequately inhibit inflammation was not determined. Second, the MV setting used in this study was not able to induce a significant enough lung injury to satisfy the diagnostic criteria for acute lung injury $\left(\mathrm{PaO}_{2} / \mathrm{FIO}_{2}\right.$ ratio $<300$ $\mathrm{mmHg}$ ). Therefore, additional studies are required to resolve the aforementioned limitations.

In conclusion, these data provide evidence of the protective effect of volatile anesthetic sevoflurane on VILI. Sevoflurane prevents enhanced expression of inflammatory mediators, and the inhibition of phosphorylation of ERK1/2 and Akt is a possible pathway for protection. Although further research on the postconditioning effects is required, the inhalation of volatile anesthetic sevoflurane may provide a new and easily applicable preventive option for protection of the lungs upon acute injury.

\section{Acknowledgments}

This work was supported by a research grant from the Research Institute of Medical Sciences, Chonnam National University (2006-CURIMS-DR001).

\section{References}

1. Dreyfuss D, Saumon G. Ventilator-induced lung injury: lessons from experimental studies. Am J Respir Crit Care Med 1998; 157: $294-323$.

2. Tremblay LN, Miatto D, Hamid Q, Govindarajan A, Slutsky AS. Injurious ventilation induces widespread pulmonary epithelial expression of tumor necrosis factor-alpha and interleukin-6 messenger RNA. Crit Care Med 2002; 30: 1693-700.

3. Frank JA, Parsons PE, Matthay MA. Pathogenetic significance of biological markers of ventilator-associated lung injury in experimental and clinical studies. Chest 2006; 130: 1906-14.

4. Fernandez-Perez ER, Keegan MT, Brown DR, Hubmayr RD, Gajic O. Intraoperative tidal volume as a risk factor for respiratory failure after pneumonectomy. Anesthesiology 2006; 105: 14-8.

5. Redel A, Stumpner J, Tischer-Zeitz T, Lange M, Smul TM, Lotz C, et al. Comparison of isoflurane-, sevoflurane-, and desflurane-induced pre- and postconditioning against myocardial infarction in mice in vivo. Exp Biol Med (Maywood) 2009; 234: 1186-91.

6. Steurer M, Schläpfer M, Steurer M, Z'graggen BR, Booy C, Reyes L, et al. The volatile anaesthetic sevoflurane attenuates lipopolysaccharideinduced injury in alveolar macrophages. Clin Exp Immunol 2009; 155: 224-30.

7. Giraud O, Seince PF, Rolland C, Lecon-Malas V, Desmonts JM, Aubier M, et al. Halothane reduces the early lipopolysaccharide-induced lung inflammation in mechanically ventilated rats. Am J Respir Crit Care Med 2000; 162: 2278-86.

8. Helmy SA, Al-Attiyah RJ. The effect of halothane and isoflurane on plasma cytokine levels. Anaesthesia 2000; 55: 904-10.

9. Kidani Y, Taniguchi T, Kanakura H, Takemoto Y, Tsuda K, Yamamoto K. Sevoflurane pretreatment inhibits endotoxin-induced shock in rats. Anesth Analg 2005; 101: 1152-6.

10. Lee HT, Ota-Setlik A, Fu Y, Nasr SH, Emala CW. Differential protective effects of volatile anesthetics against renal ischemia-reperfusion injury in vivo. Anesthesiology 2004; 101: 1313-24.

11. Kwak SH, Choi JI, Park JT. Effects of propofol on endotoxin-induced acute lung injury in rabbit. J Korean Med Sci 2004; $19: 55-61$.

12. Held HD, Boettcher S, Hamann L, Uhlig S. Ventilation-induced chemokine and cytokine release is associated with activation of nuclear factor-kappaB and is blocked by steroids. Am J Respir Crit Care Med 2001; 163: 711-6.

13. Tsuno K, Miura K, Takeya M, Kolobow T, Morioka T. Histopathologic pulmonary changes from mechanical ventilation at high peak airway pressures. Am Rev Respir Dis 1991; 143: 1115-20.

14. Allen GL, Menendez IY, Ryan MA, Mazor RL, Wispe JR, Fiedler MA, et al. Hyperoxia synergistically increases TNF-alpha-induced interleukin-8 gene expression in A549 cells. Am J Physiol Lung Cell Mol Physiol 2000; 278: L253-60.

15. Dreyfuss D, Ricard JD, Saumon G. On the physiologic and clinical relevance of lung-borne cytokines during ventilator-induced lung injury. Am J Respir Crit Care Med 2003; 167: 1467-71.

16. Ricard JD, Dreyfuss D, Saumon G. Production of inflammatory cytokines in ventilator-induced lung injury: a reappraisal. Am J Respir Crit Care Med 2001; 163: 1176-80.

17. Vlahakis NE, Schroeder MA, Limper AH, Hubmayr RD. Stretch induces cytokine release by alveolar epithelial cells in vitro. Am J Physiol 1999; 277: L167-73. 
18. Pugin J, Dunn I, Jolliet P, Tassaux D, Magnenat JL, Nicod LP, et al. Activation of human macrophages by mechanical ventilation in vitro. Am J Physiol 1998; 275: L1040-50.

19. Hsu JT, Kan WH, Hsieh CH, Choudhry MA, Bland KI, Chaudry IH. Role of extracellular signal-regulated protein kinase (ERK) in 17betaestradiol-mediated attenuation of lung injury after trauma-hemorrhage. Surgery 2009; 145: 226-34.

20. Li LF, Liao SK, Lee CH, Huang CC, Quinn DA. Involvement of Akt and endothelial nitric oxide synthase in ventilation-induced neutrophil infiltration: a prospective, controlled animal experiment. Crit Care 2007; 11: R89.

21. Uhlig U, Fehrenbach H, Lachmann RA, Goldmann T, Lachmann B, Vollmer E, et al. Phosphoinositide 3-OH kinase inhibition prevents ventilation-induced lung cell activation. Am J Respir Crit Care Med 2004; 169: 201-8.

22. Röhm KD, Wolf MW, Schöllhorn T, Schellhaass A, Boldt J, Piper SN. Renal integrity in sevoflurane sedation in the intensive care unit with the anesthetic-conserving device: a comparison with intravenous propofol sedation. Anesth Analg 2009; 108: 1848-54.

23. Rohm KD, Wolf MW, Schollhorn T, Schellhaass A, Boldt J, Piper SN. Short-term sevoflurane sedation using the Anaesthetic Conserving Device after cardiothoracic surgery. Intensive Care Med 2008; 34: 1683-9.

24. Cho EJ, Yoon JH, Hong SJ, Lee SH, Sim SB. The effects of sevoflurane on systemic and pulmonary inflammatory responses after cardiopulmonary bypass. J Cardiothorac Vasc Anesth 2009; 23: 639-45.

25. Lee HT, Kim M, Jan M, Emala CW. Anti-inflammatory and antinecrotic effects of the volatile anesthetic sevoflurane in kidney proximal tubule cells. Am J Physiol Renal Physiol 2006; 291: F67-78.

26. Yue T, Roth Z'graggen B, Blumenthal S, Neff SB, Reyes L, Booy C, et al. Postconditioning with a volatile anaesthetic in alveolar epithelial cells in vitro. Eur Respir J 2008; 31: 118-25.

27. Abou-Elenain K. Study of the systemic and pulmonary oxidative stress status during exposure to propofol and sevoflurane anaesthesia during thoracic surgery. Eur J Anaesthesiol 2010; 27: 566-71.

28. Kotani N, Takahashi S, Sessler DI, Hashiba E, Kubota T, Hashimoto H, et al. Volatile anesthetics augment expression of proinflammatory cytokines in rat alveolar macrophages during mechanical ventilation. Anesthesiology 1999; 91: 187-97. 